\title{
Fingerprinting of the Acacia nilotica (L.) Bark Extract Having Antibacterial Property
}

\author{
Jayshree D. Patel ${ }^{1}$, Nirmal S. Sahay ${ }^{2}$ and Vipin Kumar ${ }^{3}$ \\ 1. Sadbhav SRISTI Sanshodhan Laboratory, SRISTI, AES Boys Hostel Campus, Nr. Gujarat University Library \& SBI Bank, \\ Navrangpura, Ahmedabad, Gujarat 380 009, India \\ 2. Chief coordinator, Sadbhav SRISTI Sanshodhan Laboratory, SRISTI, AES Boys Hostel Campus, Nr. Gujarat University Library \& \\ SBI Bank, Navrangpura, Ahmedabad, Gujarat 380 009, India \\ 3. Director, National Innovation Foundation-India, Sattelite complex, Near Mansi cercle, Ahmedabad, Gujarat 380 015, India
}

Received: February 17, 2014 / Accepted: March 5, 2015 / Published: March 31, 2015.

\begin{abstract}
Acacia nilotica (L.) Delile, commonly known as "Babul", is reported for its medicinal property since ages. Plant is recognized for its medicinal use in traditional practices. For the study, phytochemicals were extracted as well as identified from four different solvents and their antibacterial property was determined. The fingerprinting was accomplished using HPTLC and the MIC (Minimum Inhibitory Concentration) was elucidated using standard protocols. Two Gram positive (Staphylococcus aureus and Bacillus subtilis) and two Gram negative (Escherichia coli and Pseudomonas aeruginosa) bacteria were selected for the antibacterial screening. The major phytochemicals identified in the extract of the bark of A. nilotica were catechin/epicatechin, ellagic acid and m-digallic acid. Excellent antimicrobial activity was found in chloroform $(40 \mu \mathrm{g} / \mathrm{mL})$ and methanol $(60 \mu \mathrm{g} / \mathrm{mL})$ extracts against Pseudomonas aeruginosa. The chloroform extracts consist of higher number of phytochemicals/bands as compared with other extracts and demonstrated significant antibacterial activity against all the test bacterial species.
\end{abstract}

Key words: Acacia nilotica, antimicrobial screening, fingerprinting, bacteria, HPTLC.

\section{Introduction}

The plant, Acacia nilotica, belongs to the Mimosaceae family. It is commonly known as "Babul" and is a native of India but is also found in western Asia and Africa. It was introduced to Australia-Northern Territory, South Australia, and Queensland in the late 1800s. Different parts of the A. nilotica, such as the bark, gum, leaves, and pods are used in different parts of world for their medicinal properties. A. nilotica bark extract is used in curing various ailments such as cancer, cold, congestion, cough, diarrhoea, dysentery, fever, hemorrhage, hemorrhoids, leucorrhea, ophthalmia, sclerosis, smallpox, asthma, bronchitis, diabetes, dysentery, diarrhea, skin diseases and tuberculosis [1, 2]. A series of experiments has been

Corresponding author: Jayshree D. Patel, Ph.D., research fields: microbiology and phytochemistry. E-mail: jdpatels@gmail.com. conducted earlier to evaluate the medicinal properties of plants in India [4], northeast México [5], South Africa [6-8], Cameroon [9]. Zampini and coworkers [14] have studied aqueous extracts of some plants against multi drug resistance bacteria and found good activity of many plants.

SRISTI (Society for Research and Initiative for Sustainable Technologies and Institutions, www.sristi.org) has scouted various practices since 1993 and maintains more than 20,000 examples of grassroots innovations and traditional knowledge practices in its data base. To validate the claims made by the traditional healers (as mentioned in Table 1) about the use of $A$. nilotica L., an initiative was undertaken to determine the growth inhibition effect of various extracts from the bark of $A$. nilotica against two Gram positive (Staphylococcus aureus and Bacillus subtilis) and two Gram negative 
Table 1 List of traditional knowledge holders as per SRISTI data base (www.sristi.org) using bark of Acacia nilotica for the cure of their cattle.

\begin{tabular}{|l|l|l|}
\hline Sr. no & Name of knowledge provider & Bark used for \\
\hline 1 & $\begin{array}{l}\text { Baldevbhai Okabhai Desai, Mehsana; Prakashbhai Kevaldas Makwana, Dahod; Gokalbhai } \\
\text { Amarabhai Rabari, Surendranagar; Veljibhai Surjibhai Asari, Sabarkantha; Babubhai Bhayalbhai } \\
\text { Patel, Valsad; Maansing Gavjibhai Garasiya, Dahod; Chithrabhai Ukabhai Dihora, Bhavnagar; } \\
\text { Khodabhai Vajabhai Bharvad, Surendranagar; Thiru Perisaminy, Thullukkankulam. }\end{array}$ & $\begin{array}{l}\text { Diarrhoea in } \\
\text { animal }\end{array}$ \\
\hline 2 & $\begin{array}{l}\text { Lubhabhai Dulabhai Hathiya, Bhavnagar; Raysing Arjanbhai Padhiyar, Junagadh; Gokulbhai } \\
\text { Rambhai Rabari, Surendranagar. }\end{array}$ & Wound in Animal \\
\hline 3 & Lubhabhai Dulabhai Hathiya, Mahuva, Bhavnagar & Abscess wound \\
\hline 4 & $\begin{array}{l}\text { Chamnabhai Kesaribhai Chauhan, Banaskantha; } \\
\text { Hirabhai Narayanbhai Parmar, Ahmedabad; Hirabhai Meghabhai Rajput, Bhavnagar. }\end{array}$ & Maggot wound \\
\hline
\end{tabular}

(Escherichia coli and Pseudomonas aeruginosa) bacteria.

In the study, phytochemicals catechin/epicatechin, ellagic acid, and m-digallic acid in the bark extract (organic and aqueous) of $A$. nilotica were identified using HPTLC. The authors' studies strengthen the claims of grass roots traditional knowledge.

\section{Materials and Methods}

\subsection{Collection and Extraction of Plant Material}

The bark of $A$. nilotica was collected from its natural habitat (semi arid regions of India), dried under shade and finally powdered using domestic grinders. The plant was identified and verified by the taxonomist at the Botanical Survey of India, Arid Zone Circle, Jodhpur (India). Aqueous extract and organic extracts were prepared using standard protocols [10] and extracts were further diluted with DMSO (dimethylsulphoxide). Amikacin, tetracycline and cefepime at concentrations $30 \mu \mathrm{g} / \mathrm{mL}$ were used as positive control; whereas DMSO was used as a negative control in these experiments [11].

\subsection{Phytochemical Analysis}

Quantitative and qualitative analysis were performed using HPTLC system (Camag, Muttenz, Switzerland) consisting of (1) TLC scanner connected to a PC running WinCATS software under MS Windows NT; (2) Linomat V Sample applicator; and (3) Photo documentation system Camag, Reprostar III as described by Patel and Kumar (2008) [12]. The chromatographic estimation was performed by spotting the extracts ( $6 \mathrm{~mm}$ band) on a precoated silica gel 60 F254 aluminum TLC plate $(10 \mathrm{~cm} \times 20 \mathrm{~cm})$. Extracts (volume-2 $\mu \mathrm{L}$ ) were applied to the TLC plate. Solvent system consisted of Toluene:Ethyl acetate:Diethylamine:Methanol:Chloroform in the ratio of 10:6:2:2:1 v/v. After spotting the plate; it was subjected to linear ascending development up to a distance of about $95 \mathrm{~mm}$ in the solvent system in Camag, Solvent system consisted was different for all plants. Densitometric scanning was carried out using Camag TLC Scanner III in the absorbance mode of wavelength $200-450 \mathrm{~nm}$, with a slit dimension of 6.00 $\times 0.30 \mathrm{~mm}$, micro and scanning speed of $20 \mathrm{~mm} / \mathrm{s}$, data resolution $100 \mu \mathrm{m} / \mathrm{step}$. After the scanning; images of the plate were taken at three different wavelengths of light (254 $\mathrm{nm}$ by UV lamp, $366 \mathrm{~nm}$ by mercuric lamp, 400-800 nm by white lamp) with the help of Photo documentation system Camag, Reprostar III [13].

\subsection{Antimicrobial Screening}

The standard strains used were Escherichia coli (MTCC 443), Staphylococcus aureus (MTCC 96), Pseudomonas aeruginosa (MTCC 741) and Bacillus subtilis (MTCC 441). A standard inoculum $0.1 \mathrm{~mL}$ volume $\left(10^{6}-10^{7} \mathrm{CFU}\right)$ of the test bacterial strain was spread on MHA (Mueller Hinton Agar) with a sterile glass spreader and allowed to dry. Then, 6 mm-diameter wells were bored in the MHA. Plant extracts were introduced into each well and allowed to stand for $1 \mathrm{~h}$ at room temperature to diffuse before incubation at $37{ }^{\circ} \mathrm{C}$ for $24 \mathrm{~h}$. The IZD (Zone of Inhibition) was measured by the antibiotic zone reader 
to the nearest mm [11]. The MIC (Minimum Inhibitory Concentration) was determined using the agar diffusion by plotting the graph of $\operatorname{IZD}^{2}\left(\mathrm{~mm}^{2}\right)$ against the log of concentration and point of intersection on the $\mathrm{x}$-axis was recorded [14]

\section{Results and Discussion}

\subsection{Phytochemical Analysis}

Bark of $A$. nilotica was extracted in water and three organic solvents. Data (Table 2) shows that the minimum extract yield was found in petroleum ether $(0.002 \%)$ whereas maximum yield was found in water $(33.28 \%)$. The literature survey showed that major phytoconstituents found in the plant were: 1-arabinose, catechol, galactan, galactoaraban, galactose, $\mathrm{N}$-acetyldjenkolic acid, sulphoxides pentosan, saponin, tannin and sugar, whereas the bark specifically contains epigallocatechin, catechol, pyragallol, mDigallic acid, gallic acid, and ellagic acid $[15,16]$. The TLC scanning of all four extracts (methanol, chloroform, petroleum ether, and water) of the bark of A. nilotica is shown in Fig. 1. The authors' phytochemical analysis of the $A$. nilotica bark extract displayed presence of three known compounds; catechin/epicatechin, ellagic acid, and m-digallic acid based on their $R_{f}$ values. The $R_{f}$ value of catechin is 0.10 , ellagic acid is $0.45, \mathrm{~m}$-digallic acid is 0.55 and there was no overlap with any other component in the analyzed sample in the range between 200-450 $\mathrm{nm}$. Chromatogram analysis showed that chloroform extract contains more numbers of phytochemicals; whereas petroleum ether extract contains only two compounds; m-digallic acid and catechin. In methanol extract m-digallic acid, ellagic acid and catechin were found. It is necessary to purify the compounds present in all the extracts for further studying their anti-bacterial properties.

\subsection{Antimicrobial Activity}

The results (Table 2) indicate that maximum inhibition was observed in chloroform extract against $P$. aeruginosa (MIC: $40 \mu \mathrm{g} / \mathrm{mL}$ ), followed by methanol extract against the same bacterial species (MIC: 60 $\mu \mathrm{g} / \mathrm{mL})$. Methanol extract against $E$. coli and petroleum ether extract against $P$. aeruginosa displayed very good inhibition (MIC: $70 \mu \mathrm{g} / \mathrm{mL}$ ). Other extracts also displayed significant antibacterial activity against screened pathogens except for methanol extract against B. subtilis and water extract against $P$. aeruginosa. These results are similar to the findings reported by Bagchi and colleagues [17]. Their group had reported that extracts of $A$. nilotica effectively inhibited growth of $E$. coli and $P$. aeruginosa but did not affect the growth of $B$. subtilis. Srinivasan and his colleagues [18] had earlier reported that aqueous extract of $A$. nilotica was effective against only $B$. subtilis but ineffective against other three bacterial species (Escherichia coli, Staphylococcus aureus, and Pseudomonas aeruginosa). The authors' results are contrary to their results in which water extracts was found effective against all the

Table 2 Antimicrobial activity of bark of Acacia nilotica extracts.

\begin{tabular}{|c|c|c|c|c|}
\hline \multicolumn{5}{|c|}{ Extracts name and control (\% yield of Zone of inhibition $(\mathrm{mm})$ at concentration $1 \mathrm{mg} / \mathrm{ml}$ excluding disc (well) region } \\
\hline extract) & Ecoli* & Saureus* & $P$ aeruginosa* & B subtilis* \\
\hline Petroleum ether extract $(0.002)$ & $4.07 \pm 0.04(140)$ & $0.53 \pm 0.06(1080)$ & $6.1 \pm 0.06(70)$ & $2.42 \pm 0.2(100)$ \\
\hline Chloroform extract (1.01) & $3.06 \pm 0.24(200)$ & $3.7 \pm 0.06(120)$ & $7.44 \pm 0.16(40)$ & $3.22 \pm 0.02(150)$ \\
\hline Methanol extract (4.55) & $4.85 \pm 0.76(70)$ & $3.7 \pm 0.05(490)$ & $6.79 \pm 0.4(60)$ & -- \\
\hline Water extract (33.28) & $2.85 \pm 0.85(120)$ & $4.52 \pm 0.82(110)$ & -- & $1.45 \pm 0.95(390)$ \\
\hline Tetracycline $(30 \mu \mathrm{g} / \mathrm{mL})$ & $16.9 \pm 0.04$ & $4.02 \pm 0.02$ & $17.9 \pm 0.06$ & $23.06 \pm 0.02$ \\
\hline $\operatorname{Amikacin}(30 \mu \mathrm{g} / \mathrm{mL})$ & $18.1 \pm 0.02$ & $8.1 \pm 0.01$ & $10.0 \pm 0.02$ & $16.1 \pm 0.02$ \\
\hline Cefepime $(30 \mu \mathrm{g} / \mathrm{mL})$ & $6 \pm 0.04$ & $0.45 \pm 0.22$ & $19.6 \pm 0.05$ & $14.03 \pm 0.04$ \\
\hline Dimethylsulfoxide & -- & -- & -- & -- \\
\hline
\end{tabular}

--: No growth inhibition. *: Minimum inhibitory concentration (MIC; in $\mu \mathrm{g} / \mathrm{ml}$ ) is given in parenthesis. 


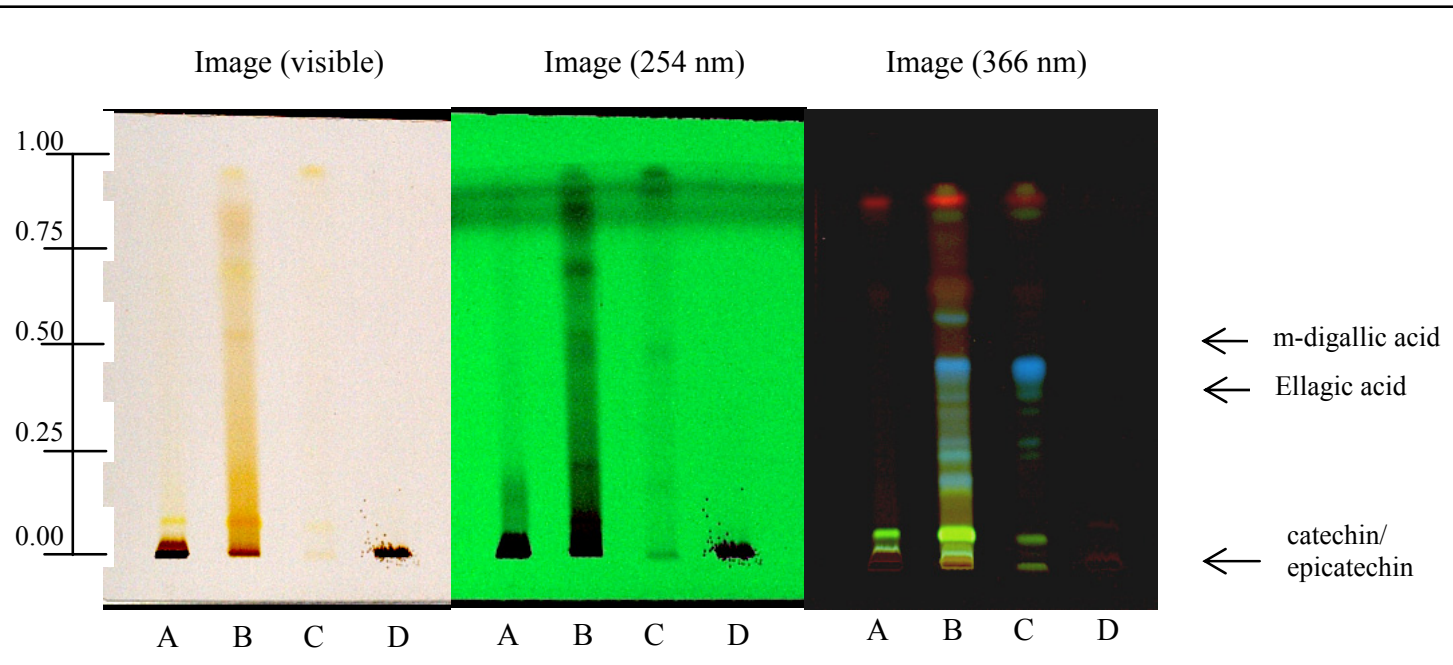

Fig. 1 Chromatograms obtained from different extracts of Acacia nilotica.

Four extracts (aqueous and organic solvent) were spotted. Spot abbreviations are described below with their application volume. A = Methanol extract $2 \mu \mathrm{l}, \mathrm{B}=$ Chloroform extract $2 \mu \mathrm{l}, \mathrm{C}=$ Petroleum ether extract $2 \mu \mathrm{l}$ and $\mathrm{D}=$ Water extracts $2 \mu \mathrm{l}$. Catechin/Epicatechin is visible at $\mathrm{R}_{\mathrm{f}}$ value of- 0.10 ; Ellagic acid at- 0.45 and m-digallic acid at- 0.55 .

above mentioned bacterial species except Ps. Aeruginosa. Deeni and Sadiq reported that methanol extract was found inhibitory to B. subtilis, Ps. aeruginosa and $S$. aureus but not effective towards $E$. coli; whereas in studies methanol extract can inhibit the growth of $E$. coli, S. aureus, and Ps. aeruginosa, whereas B. subtilis is resistant to the methanol extract [19].

The present study has highlighted the bark extract of A. nilotica to control pathogenic bacteria grown based on the basic information of grass roots traditional knowledge as per Table 1. Results clearly indicate the antibacterial activity of the aqueous and organic extract of $A$. nilotica. The study will help to develop potential herbal medicine for infections such as extra intestinal infections, skin diseases, acute food poisons and post surgery infections commonly caused by $E$. coli, $S$. aureus, B. subtilis, and Ps. aeruginosa. The food and medicines of the indigenous people mostly constituted of native plants, which may have helped them to combat many microbial diseases. The current study supports this hypothesis.

\section{Acknowledgement}

The authors are thankful to Prof. Anil K. Gupta for honorary supervision and support to carry out this research. Authors are deeply thankful to scouts, Ashok B. Vaghela; Balvantsinh L. Zala; Bhikhubhai K. Dhapa; Champaben M. Gavit; Dilip B. Chavda; Ishwarbhai S. Kiradiya; Lakshman Garasiya; Manish R. Purohit; Manubhai M. Thakor; Mukesh B. Sonara; Rajubhai V. Desai; Ramesh Shrimali; Rameshbhai B. Vaghela and Shankarbhai V. Gamar for scouting these practices. They are also thankful to Sadbhav Foundation Mumbai for their capital support to the lab.

\section{References}

[1] Tarmuzy, Z. 2009. "Impact of Acacia nilotica on Environment at National Baluran Park, East Java, Indonesia." Buenos Aires 1-9.

[2] Misar, A., Bhagat, R., and Mujumdar, A. M. 2007. "Antidiarrhoeal Activity of Acacia nilotica Willd. Bark Methanol Extract." Hindustan Antibiot Bull 49-50 (1-4): 14-20.

[3] Banso, A. 2009. "Phytochemical and Antibacterial Investigation of Bark Extracts of Acacia nilotica." J. Med. Plants Res. 3 (2): 082-5.

[4] Hemamalini, Jithesh, and Nirmala, 2013. "Phytochemical Analysis of Leaf Extract of Plant Acacia nilotica by GCMS Method." Adv. Biol. Res. 7 (5): 141-4.

[5] Molina-Salinas, G. M., Pérez-López, A., Becerril-Montes, P., Salazar-Aranda, R., Said-Fernández, S., and Waksman, de T. N. 2007. "Evaluation of the Flora of Northern Mexico for in vitro Antimicrobial and Anti Tuberculosis Activity." J. Ethnopharmacol. 109 (3): 435-41. 
[6] More, G., Tshikalange, T. E., Lall, N., Botha, F., and Meyer, J. J. M. 2008. "Antimicrobial Activity of Medicinal Plants against Oral Microorganisms." $J$. Ethnopharmacol. 119 (3): 473-7.

[7] Van Vuuren, S. F. 2008. "Antimicrobial Activity of South African Medicinal Plants.” J. Ethnopharmacol. 119 (3): 462-72.

[8] Van Vuuren, S. F., and Naidoo, D. 2010. "An Antimicrobial Investigation of Plants Used Traditionally in Southern Africa to Treat Sexually Transmitted Infections." J. Ethnopharmacol. 130 (3): 552-8.

[9] Beng, P., Rohmer, M., and Tsamo, E. 2010. "In vitro Antimicrobial Activity of Extracts and Compounds of Some Selected Medicinal Plants from Cameroon." $J$. Ethnopharmacol. 128 (2): 476-81.

[10] Patel, J. D., Patel, D. K., Shrivastava, A., and Kumar, V. 2008. "Screening of Plant Extracts Used in Traditional Antidiarrhoeal Medicines against Escherichia coli." Scientific World 6: 63-7.

[11] Patel, J. D., Shrivastava, A., and Kumar, V. 2009. "Evaluation of Some Medicinal Plants Used in Traditional Wound Healing Preparations for Antibacterial Property against Some Pathogenic Bacteria." J. Clinic Immunopathol Res. 1 (1): 007-12.

[12] Patel, J. D., and Kumar, V. 2008. "Annona squamosa L.: Phytochemical Analysis and Antimicrobial Screening." $J$. Pharmac Res. 1 (1): 34-8.

[13] Patel, J. D., Kumar, V., and Bhatt, S. A. 2009. "Antimicrobial Screening and Phytochemical Analysis of Resin Part of Acacia catechu." Pharmaceutic boil 47 (1):
34-7.

[14] Ofokansi, K. C., Attama, A. A., Uzor, P. F., and Ovri, M. O. 2013. "Evaluation of the Combined Antimicrobial Activity of the Leaf Extract of Phyllantus Muellerianus with Ciprofloxacin." J. Pharma Tech Drug Res. 2-16.

[15] Chaubal, R., Deshpande, V. H., and Deshpande, N. R. 2005. "Methyl Gallate, the Medicinally Important Compound: A Review." Electron. J. Environ. Agric. Food Chem. 4 (4): 956-62.

[16] El-toumy, S. A., Mohamed, S. M., Hassan, E. M., and Mossa, A. H. 2011. "Phenolic Metabolites from Acacia nilotica Flowers and Evaluation of Its Free Radical Scavenging Activity." Journal of American Science 7 (3): 287-95.

[17] Bagchi, G. D., Singh, A., Khanuja, S. P. S., Bansal, R. P., Singh, S. C., and Kumar, S. 1999. "Wide Spectrum Antibacterial and Antifungal Activities in the Seeds of Some Coprophilous Plants of North Indian Plains." $J$. Ethnopharmacol. 64: 69-77.

[18] Srinivasan, D., Nathan, S., Suresh, T., and Perumalsamy, P. L. 2001. "Antimicrobial Activity of Certain Indian Medicinal Plants Used in Folkloric Medicine." $J$. Ethanopharmacol. 74: 217-20.

[19] Deeni, Y. Y., and Sadiq, N. M. 2002. "Antimicrobial Properties and Photochemical Constituents of Leaves of African Mistletoe (Tapinanthus dodoneifolius (DC) Danser) (Loranthaceae): An Ethnomedicinal Plant of Hausaland, Northern Nigeria." J. Ethnopharmacol. 83: 235-40. 